\title{
光学玻璃熔制的發展及其有关原理
}

\author{
襲 祖 同
}

（中国科学院光学棈嘧机械仪器研究所）

光学玻璃的制造自法国紀南 [1] (P. L. Guinand) 算起，已近二百年了。1768 年紀南在法国 Le Roulet 开始試驗光学玻琌，發展成为現在巴黎郊外的 Para-Montois 光学玻璃厂。1848 年英国在 Birmingham 試制光学玻璃; 1881 年德国在 Jena 建立了 Schott 玻璃厂，以試驗光学玻唡作为首要任务。第 一次世界大战时美国曾对光学玻璃投入了較大力量来 供应需要。苏联白十月革命成功后很重視这个問題[2], 保証了衛国战争中的供应。1941一1945 年閒澳洲、加 拿大亦建立了制造厂，在同时期內美国作了更大規模 的扩充。

我国于解放后，由于党和政府的重視，已开致了 这方面的工作, 首先在中国科学院工学館 (現改名为 治金陶瓷研究所) 开端, 后在仪器邻 (現改名为光学 精泌机械仪器研究所) 进行了研究試制。在試制中自 行設棓讲建立了一套完整設备, 解决了一系列的技术 問題，获得了一定的成就。現在这項工作已向工業部 門推广，初步証明試制中的經驗，对工業起着巨大作 用，使工業部門能很快地、順利地进入正䂓生产。

在仪器館的光学玻璃試制中，参加工作者达一百 人, 抹且得到仪器館党政領导上的大力支持和不断指 导，在技术方面得到王大珩先生的許多帮助，新中国 光学玻唡制造工業的成长应归功于他們。本文的內容 能够有一定的实踐基础，亦应问他們表示感謝。

\section{一 光学成像对光学玻峦的要求 决定了光学玻璃發展的方向}

人类用来揭蹼自然界秘密的工具, 首先要算光学 仪器, 例如利用显微鏡覌察到了微生物, 利用天文望 远鏡發現了遥远的天体。用来成像的光学系統須滿足 多种多样的要求，因之对光学玻璃也提出了一定的要 求。

\section{（一）对光学玻璃光性的要求}

本交所述光学玻璃是指無色透明的光学玻唡, 不 包括滤光片。

1. 消除光学系統的球差和色差时常利用光学常数 不闰的玻琌。单一正薄透鏡的球差总是欠校正的, 单一 負薄透鏡的球差总是过校正的(圖 1)。一个簡单物鏡
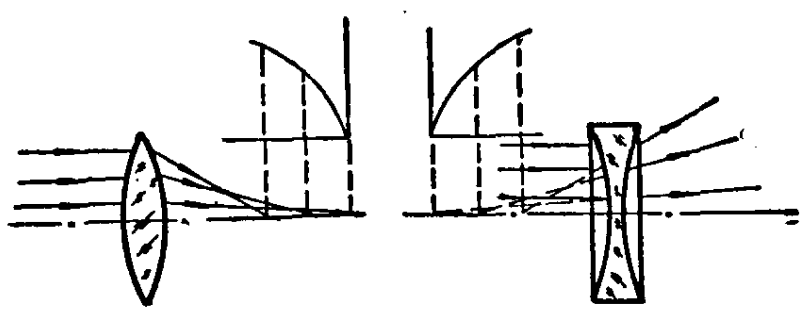

a

16

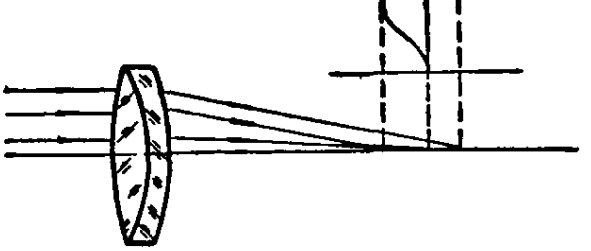

$1 c$

图 1 1a. 正唀鏡球差; 1b. 負唀鏡球差; 1c. 胶合透鏡球差。

要校正球差就須用两种折射率不同的玻唡来制造正負 透鏡，配合起来去消除球差。穿过光学系統的光綫通 常是無色的白光, 就是多色組成的光耐不是单色光。 由于玻璃对各色光的折射不同，使所成的像带有出差 而模糊不清。要校正色差必須选色散不同的玻琌制成 正負透鏡配合起来使用。以上是光学成像最起碼的要 求，就对光学玻釉提代了不同折射乲、不同色散的多 品种性的要求。

2. 消除二級光譜需要相对部份色散相同的玻璃。 高質量的显微鏡头及天文望远鏡头，除消去一粐光譜 外还要求消除二极光譜，即除了消去对 $C$ 綕、 $F$ 綫的 色差外还要求消除对第三譜綫（通常是 $D$ 䋊）的色 差。于此要求不同的 $n_{D}$ (对 $D$ 綫的折射察) 和 $V_{D}$ （相对色散倒数，即 $\left(n_{D}-1\right) /\left(n_{F}-n_{C}\right)$ 的玻珓具有 相同的相对部份色散。通常火石玻璃的色散总是使兰 端光譜的相对伸張較冕玻璃的为长,不符合上述要求。 要滿足要求須寻找特种成分，例如在火石玻倒配料內 引用較大量的 $\mathrm{Sb}_{2} \mathrm{O}_{3}$ 。

3. 减少光学設計的劳动量需要 $n_{D}$ 相同而 $V_{D}$ 不 同的玻璃。1886 年左右阿貝 (E. Abbe) 引用精确的 三角計算方法来設計光学系統后，每一新系統在投入 生产前先加以往复計算，有时需要很大量的芬动承校 正各种各級的像差,为了在一定程度上减少这种荕动， 往往暫不管系統的色差而先对五个单色像美（球差、 
彗差、缘散、場曲、畸变）进行校正，然后选捽折射 禹 $n_{D}$ 相同而色散不同的光学玻球, 用到計算中去, 使五个单色饮差仍保持于零或在一定限度之內，而把 色茩校正到合乎要求。这就要求有 $n_{D}$ 相同而 $V_{D}$ 不 同的光学玻琌, 如圖 2 里本行于 $V_{D}$ 軸的直綫上的玻 唡。

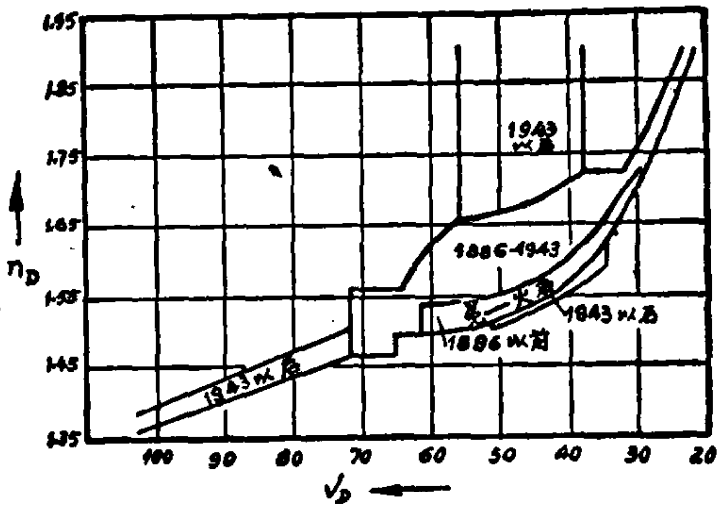

圆 2 光学皮璃弦展历史, $n_{D}$ 是对 $D$ 綫的折射率，

$$
V_{D}=\left(n_{D}-1\right) /\left(n_{F}-n_{C}\right)
$$

4. 筧視場、大孔徑鏡头需要 $n_{D}$ 与 $V_{D}$ 都高的玻 琌。光学系統里折射面对光的聚敛或墢散作用依賴 于折射面的曲率和前后折射來的差別。如圖 3 所示, 我們可将透鏡的边緣部分当作三棱鏡来看。光 $\mathrm{SM}$ 通过透鏡所受到的编折 $\delta$ 当㮦鏡角 $a$ 小的时候可用

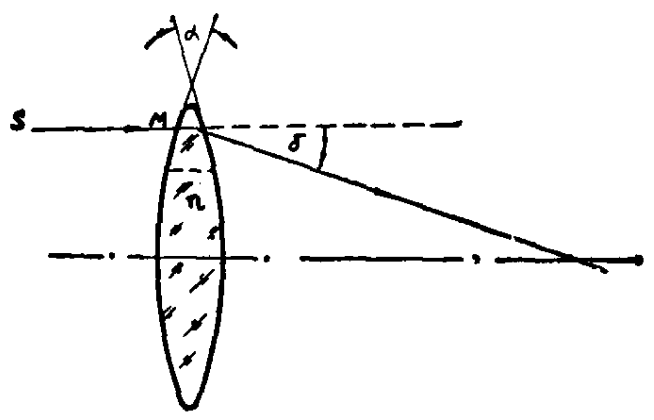

国 3 透鏡当作三棱篭来看

$\delta \cong a(n-1)$ 来表示。要达到一定的编折 $\delta$, 則当 $n$ 小 的时候， $a$ 就需要大， $a$ 大了折射面的曲本就要随着 㙁火; 但曲率的增大将抬高玻琌的冷加工成本, 而且 对高数球募也是不利, 从而限制了光学系相对孔徑的 加大。所以人們从另一条道路 (即提高折射索) 来寻 求解决是有理由的。同时筧角度的航空㨖影鏡头, 由 于視場角的突出地寬广，迫切需要决定像場弯曲的 “Petzval 和”的降低，而这个和是与透鏡玻玹的折射 率成反比的，因此更增加了提高折射爽要求的迫切程 度。但光学系統必須校正色差, 所以提高 $n_{D}$ 的同时, 必須設法降低色散 $\left(n_{F}-n_{C}\right)$ 。新型的含 $\mathrm{TiO}_{2} 、 \mathrm{TeO}_{2}$ 、 $\mathrm{MoO}_{3} 、 \mathrm{~V}_{2} \mathrm{O}_{5}$ 等的玻玹折射本虽很高 $\left(n_{D}=2-5\right)$ 但 色散太高, 而且揢制閣題未解决, 所以仍無法使用。 氞系玻璃色散很低, $\left(n_{F}-n_{C}=0.0039-0.0051, V_{D}=\right.$ $82-100)$, 但折射來很小 $\left(n_{D}=1.39-1.42\right)$, 所以仅
在特殊情况下应用。达到高折射而低色散的目的, 在 第一阶段(1886年)主要是引用了氧化銀 $(\mathrm{BaO})$ ，在第 二阶段 (1941年)主要是引用了三氧化二锠， $\left(\mathrm{La}_{2} \mathrm{O}_{3}\right)$, 从而使由㢸长的老的筧一火石区域 (圖 2 ),

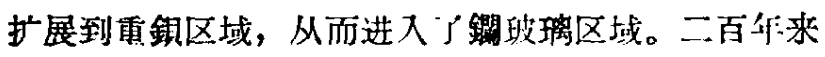
光学成像对高 $n_{D}$ 和高 $V_{D}$ 的裂求, 促使对周期表中 的各元素广泛地作熔融試驗, 到目前为止桱过試驗泟 明可以参加熔成無色玻琌的元素有鋰、铍、㗅、氧、

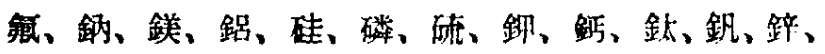

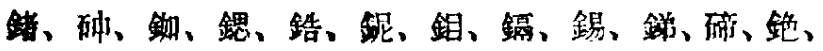
鋇、銅、钽、銪、釷、鉛、铋、針、釮等 37 秒。

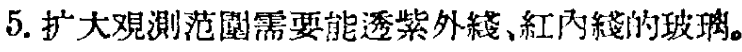
光学仪器的分辨極限被 $\lambda / n \sin u$ 所决定( ，是被用作 覌祭工具的光的波长, $n$ 是物空閏的折射承， $u$ 是 物光的最大孔徑角)。当 $\lambda$ 减小时这極限亦减小, 就 是分辨本領增大。例如紫外光显微鏡的分辫本領高出 可見光显微鏡一倍左右，这就对玻瑞提出了透紫外耤 的要求。同时紅內綫在覌測上的应用日漸成熟，因之 对玻璃提出了透紅內緎的要求。此外, 紫外、紅內的 光譜仪器上要求能透紫外、紅內光綏的玻琌, 而且要 求色散較大的玻璃来作色散棱鏡。

\section{（二）对光学玻璃常数公美、透明度、} 均匀性、表面抗蝳性的要求

在光学系統的設計中，假定了在洞一种介筫里光 綫的直綫傳播定律, 当光綫从一种介临进入另外一种 介質时則应用了折射定律。在这里澈言十者假定了每一 个介質具有一定的光学常数, 而且假定了介質的透明 度、均匀性、表面抗蝕性。但是实际上吸收、不均匀 﨡、不抗蝕性总是不可完奎避免的、光学常数总是有 小偏差的。下面談一下主要的、力求要除的缺陷。

1. 光学常数的偏差。光学設計者往往从光学玻㻦 目录中获得玻璃的光学常数，但实际制造时所获得的 玻璃它的光学常数总是和月录所給的有些差別。产生 差别的原因: (1) 原料成分的化学分析及水分测定的 骙差;（2）熔炼中各氧化物的不同揮發登及此珮、挩

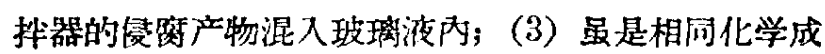
分的玻璃但因热处理的过程不同也会产生光学常数的 编差。这编差使实际减像不合没訃时预期的結果而影 响像的質量。

2. 气泡、結石、颜色。玻琌里的气泡、結石能反 射、繞射和散射經过它們的光綫, 使光强度降低而椇 失像的完度和清晰度。在气泡、結石的周国同时易有 內应力存在。玻璃的㭚色是由于玻玹里的某些夹杂 物（例如 $\mathrm{Fe}_{2} \mathrm{O}_{3}$ ）不均匀地吸收各种波长的光能浩成 的，結果也是降低像的亮度，井使像着色。

3. 条紋。最有害于成像品質的是玻琌中的条紋。 
这些条敉的化学成分和它四周的微有不同，因而它的 折射本亦有微差。为估計其影响起見, 假定条的横 截面是一个圆 (圖 4 ), 光馢以 $45^{\circ}$ 角入射，則光綫所

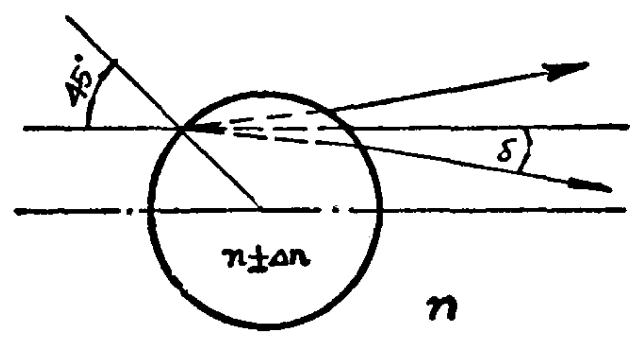

回 4 表示光絨案过条紋时的偏折

受这条紋的偏折 $\delta$ 近似地等于 $2 \Delta n / n$, 其中 $\Delta n$ 是条 紋的折射率与其周園的之間的微差。若 $n=1.5, \Delta n=$ $10^{-6}$, 則 $\delta=1.3 \times 10^{-6}$ 弧度。这說明混杂的条粒使 成像的光綫不走直綫而起混乱，亦即是使像的涌散盘 增大而模糊。

4. 內应力及密度不均。玻璃是不良导热体, 若从 㟫温冷却下来，过速地通过其轉变点 $T_{g}$, 則 各部分 会产生压应力或拉应力，因而产生不規則、有力向性 的折射本，造成双折射。若綏慢地通过轉变区域，使 其各部分处在热平衡状态下，但却处在不同温度的热 可衡下，則各部分虽可沼有內应力，但因不同平衡温度 下玻璃密度有微差, 故相应的折射率也不一致。光綫 在折射率有梯度的介質中不走一条直綫而走弯路。这 种双折射和走弯路都使成像不清哳。

5. 玻璃的表面不抗蛤性。这不抗蝕性主要表現于 光学部件接触潮湿空气和酸碱性液体时或寄生有微生 物时，其表面受到侵蝕、腐蝕，从而光潔度遭到破坏。 这表面光潔度的被破坏，垻加了表面的漫散射，使透 明度遭受損失。

\section{二 光学玻淿揢制上的物理和化学問題}

光学成像对光学玻琌的謷求已这样地多种多样, 要制出合乎要求的玻琌，就在原料、持堝、熔嘘与熔 性方面提出了一系列的物理和化学問題。

$$
\text { （一）原 料 }
$$

寻找具有不同折射率和色散的光学玻璃配方，要 参考各单元組份吸收光譄資料，粇从实驗求出各单元 粗份的个别折射率来, 用到折射本領的公式中去, 作 为解决实际問題的指导。無色光学玻璃要求在可見光 区域內沒有吸收綫和带。一般金屬在可見光进入它时 就被吸收（由于光电效应及分子、电子的散射）。牛金 罣如矽、鍺則吸收較小，对紅內糐吸收更小。一般矽 酸盐、嗍酸盐、磷酸盐、鍺酸盐及某些丮化物則在可 見光氾圍內沒有吸收綘带，所以上迅化合物在光学玻 璃制造中用涂最广。

考虑了玻琌的光性外，还要考虑其可熔性及抗析
晶性。实际适用于生产的熔炼工具仅能在 $1500^{\circ} \mathrm{C}$ 上

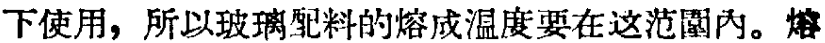
成后的玻璃态要能保持下来，就是說，玻璃冷却后必 須保持透明, 这就要求玻璃析晶湿度必須落在玻璃粘 度已大而不易析晶的区域里，或是境，不要熔成玻理 在冾却过程中有析出微晶的机会, 因为微晶散射光樹 而使玻璃失掉透明性。受到以上限制所以現有的光学 玻璃品种仍是不多。

計算玻唡折射高和色散的公式如 Huggins-孙覌 汉 [3]、Демкина[4]所用的都牵涉到玻璃勂度及其組份 的密度, 在各組份泌度間的相互影响份未透徽研究的 今天, 为了簡单而易于比較起見, 这里采用下列相加 性的計算法:

熔成玻璃的折射桼

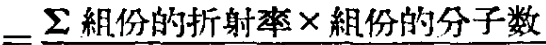

熔成玻璃的色散

$=\frac{\Sigma \text { 組份的色散 } \times \text { 組份的分子数 }}{\Sigma \text { 組份的分子数 }}$

苏联学者 A. A. Аппен[5]曾給出了下表:

\begin{tabular}{l|c|c}
\hline 粗 & 份份的折射率 $n_{D}$ & 組份的色散 $\left(n_{F}-n_{C}\right)$ \\
\hline $\mathrm{SiO}_{2}$ & $1.4585-1.475$ & 0.00675 \\
$\mathrm{TiO}_{2}$ & 2.15 & 0.06000 \\
$\mathrm{~B}_{2} \mathrm{O}_{3}$ & $1.710-1.470$ & $0.00900-0.00640$ \\
$\mathrm{Al}_{2} \mathrm{O}_{3}$ & 1.525 & 0.00850 \\
$\mathrm{BeO}$ & 1.595 & 0.00890 \\
$\mathrm{MgO}$ & 1.570 & 0.01110 \\
$\mathrm{CaO}$ & 1.730 & 0.01480 \\
$\mathrm{SrO}$ & 1.775 & 0.01630 \\
$\mathrm{BaO}$ & 1.885 & 0.01890 \\
$\mathrm{ZnO}$ & 1.700 & 0.01650 \\
$\mathrm{CdO}$ & 1.865 & 0.02600 \\
$\mathrm{PbO}$ & $2.150-2.350$ & $0.05280-0.07440$ \\
$\mathrm{Li}_{2} \mathrm{O}$ & $1.695(1.660) *$ & 0.01340 \\
$\mathrm{Na}_{2} \mathrm{O}$ & $1.590(1.575)$ & 0.01420 \\
$\mathrm{~K}_{2} \mathrm{O}$ & $1.575(1.595)$ & 0.01300 \\
$\mathrm{As}_{2} \mathrm{O}$ & 1.57 & 0.01600 \\
$\mathrm{Sb}_{2} \mathrm{O}_{3}$ & 2.55 & 0.07700 \\
\hline
\end{tabular}

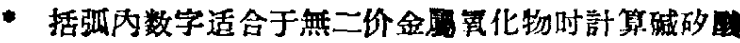
盐之用。

根据已發表的特别是近年来的玻璃光性数据，作 者整理出以下的补冭表。

\begin{tabular}{l|l|l|r}
\hline 租 & 組份的折射率 $n_{D}$ & 租份的色散 $n_{F}-n_{C}$ & 有效范回 \\
\hline $\mathrm{La}_{2} \mathrm{O}_{3}$ & 2.55 & 0.038 & $5-40 \%$ \\
$\mathrm{GeO}_{2}$ & 1.68 & 0.018 & $50-100 \%$ \\
$\mathrm{P}_{2} \mathrm{O}_{5}$ & 148 & 0.0048 & $50-80 \%$ \\
$\mathrm{TeO}_{2}$ & 2.20 & 0.060 & $50-100 \%$ \\
$\mathrm{TaO}_{2}$ & 2.10 & 0.054 & $0-30 \%$ \\
& 1.75 & 0.030 & $0-25 \%$ \\
\hline
\end{tabular}


这补充表是根据不多的实騟数据得出来的，精度是不 的，但从以上两表可以看到: 符合折射㭃高而色散 低的要求的，第一是等化鋇，这是 1886 年左右所引用 进去的; 第二是三氧化蟩，这是 1940 年左右所引用 进去的, 这标志着光学玻粫的两大發展。

从 $\mathrm{SiO}_{2} 、 \mathrm{~B}_{2} \mathrm{O}_{3} 、 \mathrm{P}_{2} \mathrm{O}_{5} 、 \mathrm{GeO}_{2}$ 四种氧化物比較看 来, 除了 $\mathrm{GeO}_{2}$ 因稀有而且是牛导体的重要原料不在 玻制造中大量应用外， $\mathrm{P}_{2} \mathrm{O}_{6}$ 具有較 $\mathrm{SiO}_{2}$ 有利的光 学常数，而且这氧化物在我国为富有，它的熔融温度 也較低，所以为了結合我国㗄源可考虑弡展 含 磷玻 唡。至于含磷玻璃的表面抗蝕性較次的問題，則可用 化学表面染膜的方法来加保护層而获得解决。稀有氧 化物 $\mathrm{La}_{2} \mathrm{O}_{3}$ 在我国将是不难获得的，这是我国發展光 学玻唡制造的有利条件。

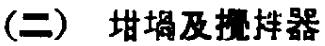

有了适当的原料而要熔成潔学的皮璃，首先要有

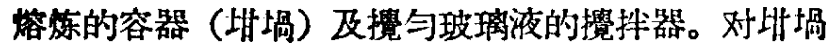
的主要要求是 (1) 在空气干燥及燒成过程中的不裂, 同时在熔炼温度下 $\left(1350-1450^{\circ} \mathrm{C}\right)$ 能承受玻璃液的 压力而不致傾埸（2）能耐玻璃液的侵蝕、简蝕而 不污染玻蔀液。在金屬方面对某些玻唡实际可用的是 饪，但我国自己不能供应，井且鉑在地球上的蘊藏量

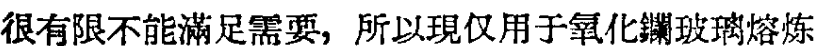
时作为㘫堝的䘞里。另外如鵭、鉬，熔点很高，但易 被氧化，即使在直空中熔炼由于玻璃料中含有桴生氧 的組份，仍难适用。在工業生产上还是粘土朴佩用得

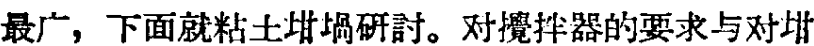
佩的相同，所以不另論远。

\section{1. 朋佩配料和成型}

(1) 圤凨原料的含鉄量。光学玻璃含 $\mathrm{Fe}_{2} \mathrm{O}_{3}$ 量 若超过 $0.02 \%$ ，則玻璃将呈現很易眼見的黃綠色。以 200 升圤堝为例，假定在熔炼过程中此佩和玻璃液 的 接触面平均被侵窝掉 $3 \mathrm{~mm}$ ，玻璃原料中的 $\mathrm{Fe}_{2} \mathrm{O}_{3}$ 含 量原为 $0.01 \%$ ，若此堝配料中含 $\mathrm{Fe}_{2} \mathrm{O}_{3}$ 为 $1 \%$ ，則由

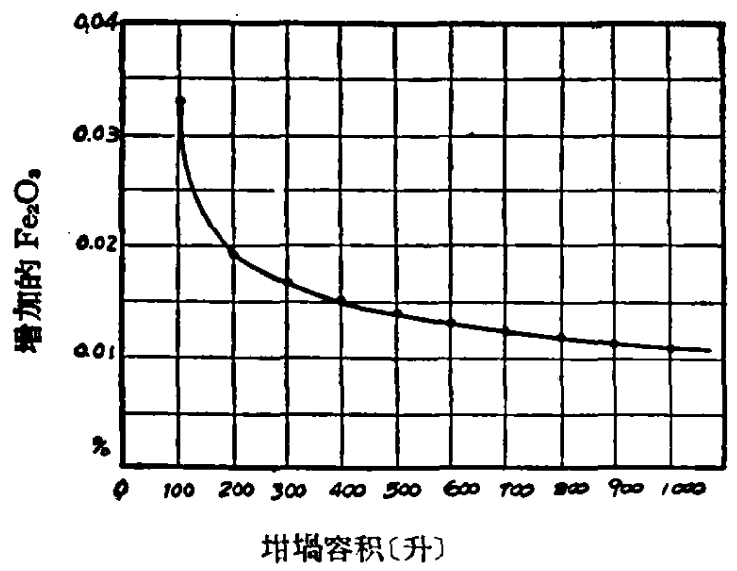

5 坩堝容积与無磨所引进的 $\mathrm{Fe}_{2} \mathrm{O}_{3}$ 的关系

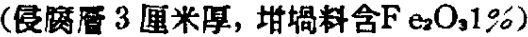

于侵窗关系，玻琌中的篻化鉄含量将由 $0.01 \%$ 垛加到 $0.03 \%$ ，已达到最大的容許会量了。此堝的大小与传 峦引入熔成玻璃內的 $\mathrm{Fe}_{2} \mathrm{O}_{3}$ 含量关系如圖 5, 由辞圆 可見 200 升的容量是最小的容許尺寸。同时怢佩中的 鉄質也增加玻璃液中的气泡，这是要求降低鉄含量的 另一理由。

（2）結合粘土。熔化玻琌成功的必要条件之一是容器的不裂, 已如上迅。在仪器館試制的初地 曾 过分重親了将佩原料含鉄量的降低，因而多用了含 $\mathrm{Fe}_{2} \mathrm{O}_{3} 0.01 \%$ 的苏州高岭土，少用了含 $\mathrm{Fe}_{2} \mathrm{O}_{3}$ 达 $2.5 \%$ 的水曲柳絬合粘士（吉林省水曲柳县产)，絬果使 此 佩在空气干燥与燒成过程中破裂达 40\%。这破裂原 因是由于圤城体內粘士太少因而結合力低，不能承受 在于燥、烧成中因局部收縮而發生的內应力。楥过增 加水曲㧕粘土从 $5 \%$ 到 $17 \%$ 后，破損等几乎降到了零。 但若使用粘士太多則沚珮容易燒場軟化不能冰受高温 下的玻瑞液的压力。我們現用的比例是粘土 8.5 比高 岭士 10 。

（3）成型、干燥、燒成。此珮配料解决后进行 成型。我婀試驗了手工望性成型、澆注成型和淿打成 型。成型的沚堝体的松紧主要决定于成型压力。以上 三种冰法中的压力，手工法受到手指力量的限制，潐 注法受到澆注压头的限制，用空气踏㮩打的压力則远

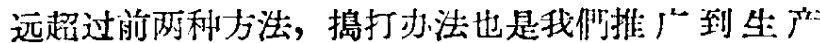
中去的。此佩成型后进行于燥。在空气中进行泊然于

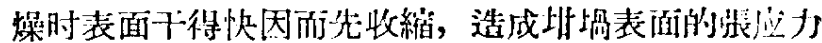
和体內的底应力，若表面張应力超过了那时候歫城士 的抗張力，則计城就起裂敉。所以在天然干燥中，千

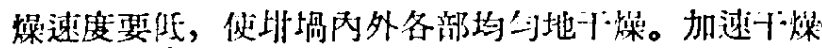

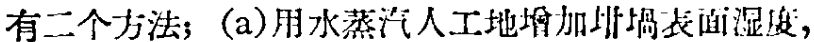

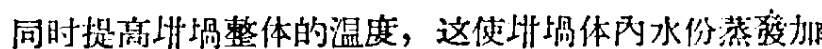
速同时延緩了表面收縮。(b) 将䧳珮体当作电组，通

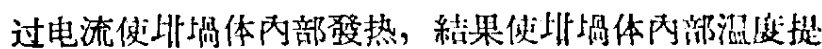

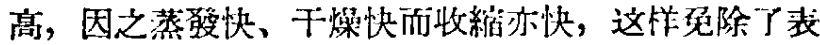
面裂紋的危險。此珮干燥完畢后进行焼成，在这过程 中于生非佩朌水阶段 $\left(450-550^{\circ} \mathrm{C}\right)$ 及燒絬收綰阶段 $\left(900-1200^{\circ} \mathrm{C}\right)$ 要延綏升温速度。若于脫水阶段北治

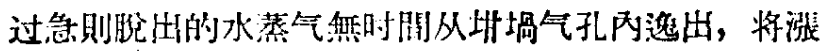
破圤珮而治成較大裂綎。我們試驗所得絬果如下表。

\begin{tabular}{|c|c|c|c|}
\hline & 手 工 & 軏 注 & 批打 \\
\hline 密 & 2.0 & 1.8 & 2.2 \\
\hline 气 孔 亨 & $19 \%$ & $28 \%$ & $10 \%$ \\
\hline
\end{tabular}

(䑁成温度 $1480^{\circ} \mathrm{C}$ )

从上表可以看到，用搗打分法所制坩佩最为紧缕。存 
这方法中配料用水仅 8\%（只有手工或焼注方法的 40\%)，因之减少了干燥中的破裂机会; 而且配成料中 的熟料在这方法里所用的較手工或潪注法的为多 (熟 料百分数: 搗打法 80 , 手工或澆注法 50), 所以这方 法减少了燒成中的焅結收縮, 也降低了拄珮的破損率。

\section{2. 减少㖼佩的侵蝕、筩蝕。}

玻琌液与坩佩壁相接触, 在这接触層里进行着不 均匀的物理、化学反应。这反应所造成的侵符产物被 玻瑞液流带到比堝內各处，污染着潔浮的玻璃液，形 成玻璃中的条紋。圤佩被侵蝕、腐蝕的速率是与圤城 接触玻唡液的面积 $F$ 成正比，与玻璃液分子和比佩料

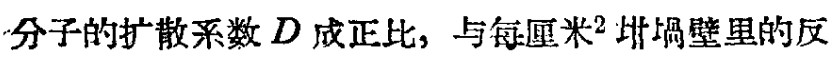
应面积 $S$ 成正比，与圤城料分子在玻琌液中的飽和 濃度 $C_{s}$ 同实际濃度 $C_{x}$ 之差 $\left(C_{s}-C_{x}\right)$ 成正比, 而与 反应居的厚度 $\delta$ 成反比。用公式来表示:

$$
\text { 侵腐速度 } \alpha \frac{F \cdot D \cdot S}{\delta}\left(C_{s}-C_{x}\right) \text { 。 }
$$

将以上理㢏宣用到实际生产中去, 得到下列各項减少 沚佩侵简的办法:

（1）减小接触面积 $F$ 。这接触面积实际上是此佩 的四壁和底的面积, 应該按它和所盛玻璃的容积相对 地来講。单独为减小壁面积起見, 則用熔池来熔化較 用踖佩有利得多，但因光学玻璃需要量一般配不上用

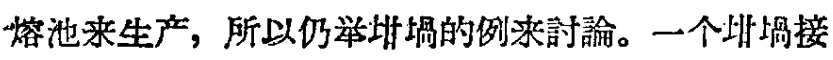
触玻璃液的面积和所盛玻璃液体积的比例是 $(2 \pi r h+$ $\left.\pi r^{2}\right) / 2 \pi r h(r$ 是将佩牛徑, $h$ 是它的內高), 对一定的 体积, 則当 $h=r$ 时, 則此比例为最小, 故耖佩高度 和它的牛徑須相接近, 以缄少相对侵寉。

（2）用燒結来减小反应面积 $S$ 。在沒有燒結的坩 堝壁上各处凹凸不平, 玻琌侵入到縫吵里去, 这样扩 大了反应面, 也可使收堝料粒被带到玻璃液里去（圖 6)。訨佩在高温下溔結瓷化以后, 气孔和减小了, 壁 面紧滵了，因之 $S$ 也減小了。这說明为什么要先将坩 堝加热到 $1480^{\circ} \mathrm{C}$ 左右保持 1一2 小时, 然后再降温添

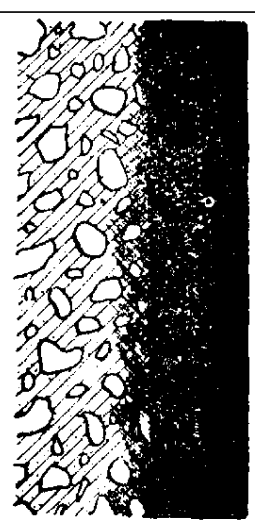

a

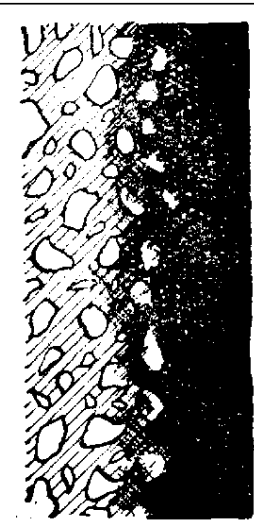

b

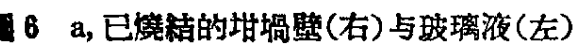

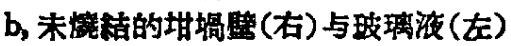

入原料。

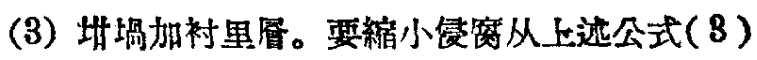
看来，可以在降低 $\left(C_{s}-C_{x}\right)$ 的数值上想办法。例如 熔化高矽質的玻璃时可用高矽質的坩城, 这样就可减 低 $C_{s}$ 和 $C_{x}$ 的差。試驗征明含矽酸高的酸性咕凨与含 矽、矹、磷酸高的酸性玻瑞所产生的侵筞是小的，反 之与含 $\mathrm{BaO}$ 高的碱性玻湠所产生的侵窝却很厉害。 所以熔化酸性玻璃时应用会演矽的酸性圤城, 塔化㖅 性玻璃时以用含矽少而含 $\mathrm{Al}_{2} \mathrm{O}_{3}$ 高的中性谁堝为迺 当; 同时高的 $\mathrm{Al}_{2} \mathrm{O}_{3}$ 合量地增加反应層的粘度。由于 高矽質和高跎質的此㶡料制备成本較高，所以可用小 量的高矽或高鋁細粒度的泥浆作为坩堝的內居祄料， 以篔加蝕抗性。

（4）适当地降低熔化温度。公式(3)中的扩散系 数 $D$ 是和 $T / \eta(T$ 是温度, $\eta$ 是粘度) 成比例的。 反应層厚度 $\delta$ 則和 $\eta$ 成比例。因之公式(3)中的 $D / 8$ 是和 $T / \eta^{2}$ 成比例。当 $T$ 增加时 $\eta$ 下降而且下降得 很快, 所以在光学玻璃熔化时尽量避免不必要的抬高 温度，相反地要适当地降低，例如重鋇玻璃熔制时， 宁可清澄温度放低些而清澄时間延长些。

（5）采用高熔点的耐火材料。熔点較高的氧化物 如等化鋯 $\left(\mathrm{ZrO}_{2}\right.$ 熔点 $\left.2720^{\circ} \mathrm{C}\right)$ 在玻璃熔融温度下它

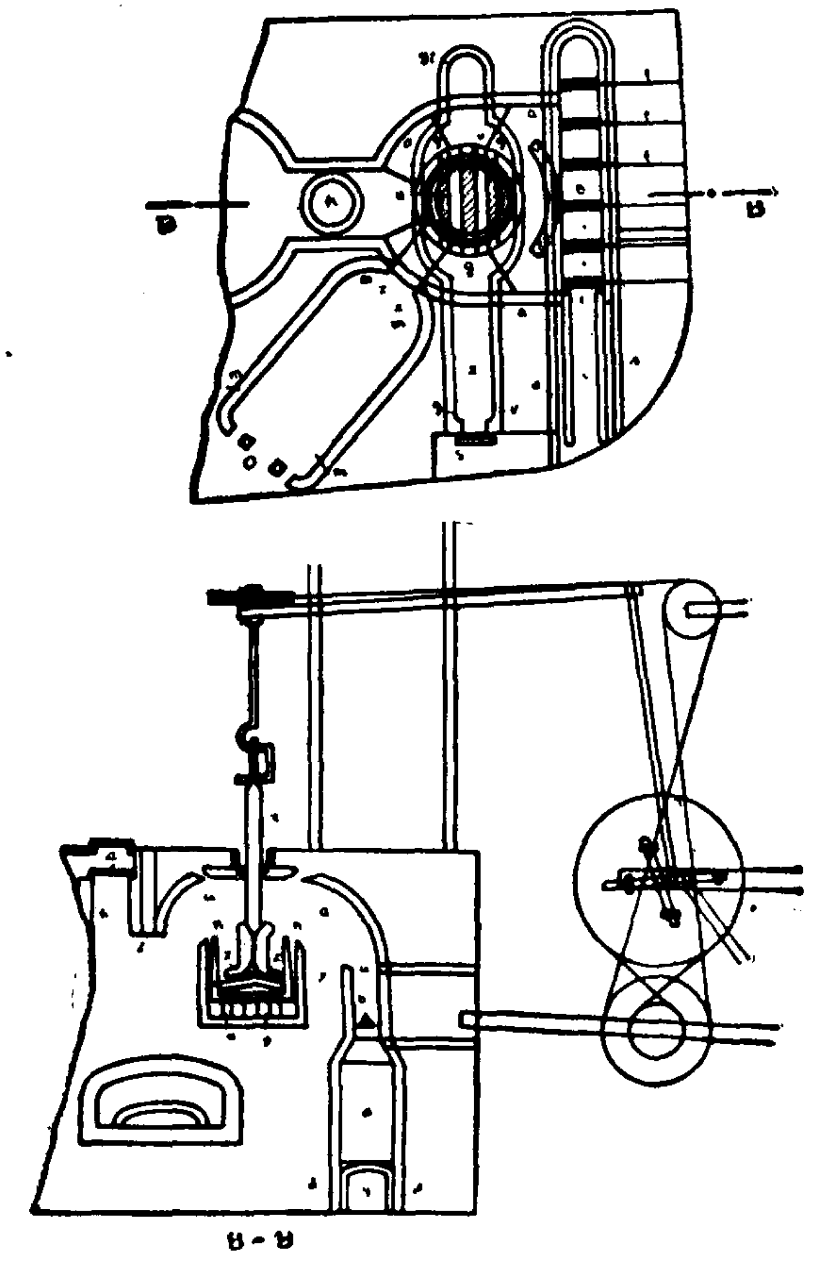

回 7 法国紀南所用结究 
与玻昞所生侵产物的粘度也較高, 从 $D / S$ 与粘度 $\eta$ 的关系看来， $\eta$ 的增加对减小侵窝起很大作用，所 以等化鋯日漸被采用到坦城制造中来。

\section{（三）熔烠与熔炼}

粉末状的配成原料，要把它变成各部分均匀的透 明体来滿足光学系統的使用要求, 就必須經过加热潄 炼过程。熔炼中首先是熔炶間題。光学玻璃的揢炼史 是 1768 年法国人紀南 (P. L. Guinand) 开始的，他 用了如圖 7 所示的熔㠊，用木材做燃料，来熔制光学 玻琌，他用的坦佩是圆桶式無頂的，从圆看来他的哳 堝預热篦和徐冷窑都与揢嘘連接在一起。随着工業用 煤的易于获得，曾有一吋期用煤作燃料，为避㣻煤烟 侵染玻璃，用了带有項盖的㘫城如圖 8。1856 年德国 人西門子 (W. Siemens) 用煤气作燃料，㓣造了空 几和媒气預热方法，使光学玻琌可用篦热式或換热式 塔嘘来熔炼，因之在技术上提高了一步。在捂集气供

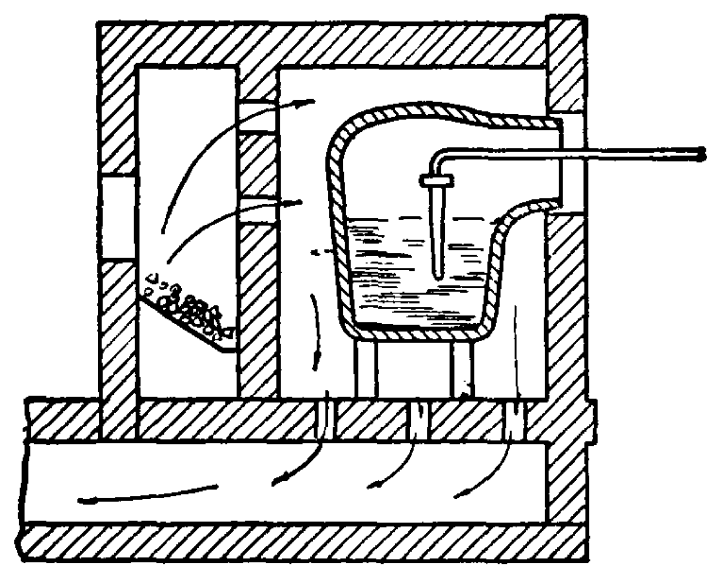

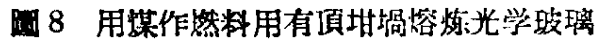

这的地方，可用燃料油来代替。近年来应用电热和离 频电热到熔炼上，将在光学玻璃的熔炼史上㖞开新的 一頁。用电加热比燃煤加热或燃油加热为潔净, 温度也 敦均匀。在用高頻加热时, 还可加一磁場, 使玻瑞液 起徽动, 以催促小气泡的逸出, 井增加玻瑞液的扩散 而消除条紋。但目前生产中使用最广泛的仍是煤气和 油, 所以下面仍按这情况来研討。

在生产实践中圆桶式無項此佩与有頂此佩都用 过。为了簡化比較起見, 我将上述二种此城画成如圖 9 的形式。在熔炼中一般是火熖包基着剒城的。在無
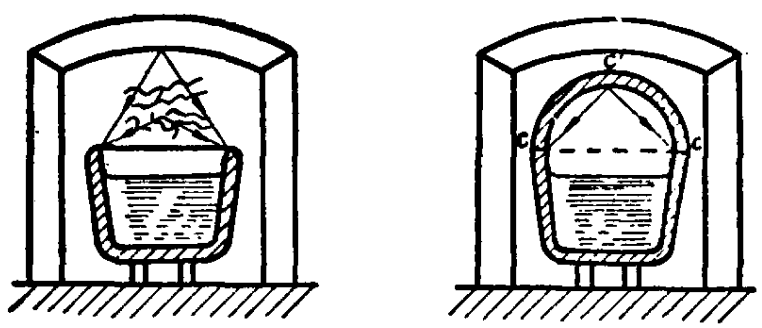

国 9 有項坩堝、無項坩堝在榕炼过程中的比較
頂圤佩內玻璃液面直接受到火焰的輻射热; 在有顶非

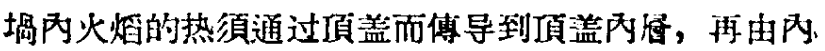
詹輻射到玻琌液面, 用經驗公式来估計玻琝液面所受 的輻射热, 得到下列比例:

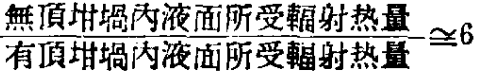

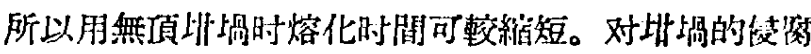

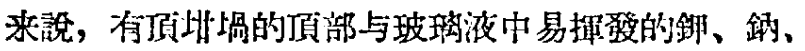
鉛、矹、矵等相接触，所生成的侵宽产物沿着圤佩䙿 項而进入玻璃，㙁添了混入玻璃液中的条紋和綠色，

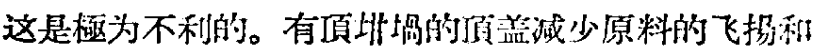
揮發, 这是一个优点, 但总算起来, 無頂垷城的优越 性是肯定的。

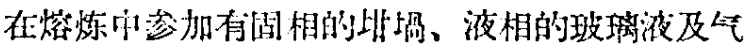
相的火菲（圖 10）。这三个相彼此作:用着，阔时也各 自进行着內部反应, 其主要內容是:

a. 訨城本身。在頂热初均 $\left(20-600^{\circ} \mathrm{C}\right)$ 失去游离 水、吸附水和化学結晶水，加热到 $575^{\circ} \mathrm{C}$ 則石英起憋 变，在900- $1250^{\circ} \mathrm{C}$ 中開迅速收維，再高则逐步燒 結。

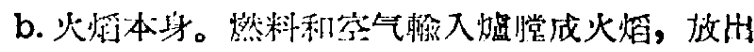
热量, 变城陵气响逸是。

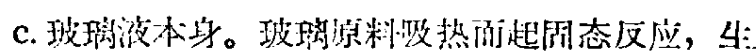

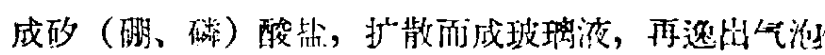
而变成透明。

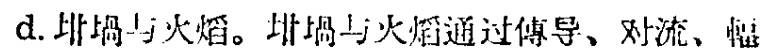
射进行热的交換, 阔时火熖气体非入杵佩的巨勫孔，

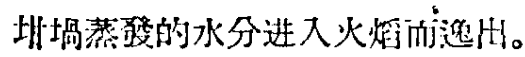

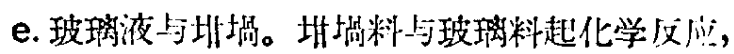

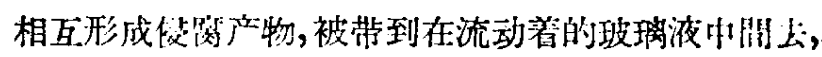
同时玻琌液也渗入到此佩壁的孔㭞內。

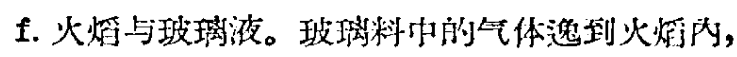
易揮發的玻虫組分蒸猺到火熖里去，火熖的灰烬御分 地落到玻玟液表面，燃燒后的撥气部分地被吸收到玻 唡液中去。

在以上本身作用及相互作用中要生产出理想的况 学玻璃, 則有着各种矛盾, 其主要的是:

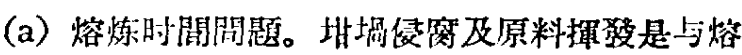
炼时偝 $t$ 成正比的:

$$
\begin{aligned}
& \text { 訨佩侵瓷总量 } \propto \int_{t_{1}}^{t_{2}} \frac{F \cdot D \cdot S}{\mathrm{o}}\left(C_{s}-C_{x}\right) d t \cdots \cdots(4)
\end{aligned}
$$

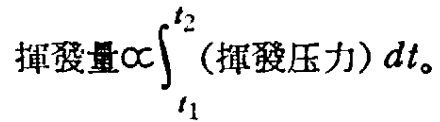

为了减少侵符及揮發, 需要縮短塔炼时閒, 但塔化和 清澄却需要一定长的时間。 
(b) 熔化温度問題。侵腐及揮發是随着温度上升 而迅速上升的。要減少侵寉及揮桴須熔制温度低些, 但强化揢虽与加速清澄却要求高的温度。

(c) 擳汼問題。为了保持玻璃液的气体吸收量以

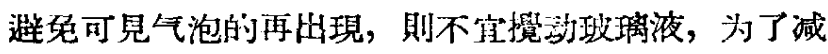

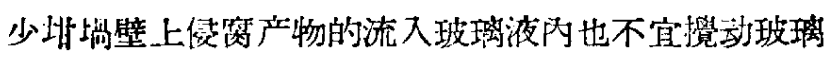
液, 但要消除条絞和原料分層, 則必須覴汼。在攪汼 速度提高时玻璃液均匀得快，分唇和条紋消除得快， 但过高了却会在指形㩭抖器行走的尾部尜进空气到玻 璃液內而造成大气泡。

以上各种矛盾的获得統一，是熔炼中要解决的科 学問題, 其关键是在协調和掌提温度时程和㩭拌时程 持且应用一些物理、化学的基体原理, 使侵窗最小, 气泡最少, 玻瑞最均匀, 尽量接近光学成像的要求。 总結过去經驗得到有效办法如下:

（1）助塎㩭拌。把原料添入訨堝后在初熔状态下 进行挖拌，使熔剂如 $\mathrm{Na}_{2} \mathrm{O} 、 \mathrm{~K}_{2} \mathrm{O}$ 等与被熔的矽砂粒 等均匀混合, 这样可加速矽 (矹、磷) 酸盐的形成及 相互扩散, 同时減少熔剂与此佩底和壁的接触, 这对 加速熔炼及减少侵窝都是有利的。

（2）化学清澄及物理清澄。清澄是指消除玻璃液 里的气泡而使之潔凈光澤。按照 stokes 定律, 气泡 上升速度与它的直徑玶方成正比。当大气泡从玻璃液 底部逐漸上浮时, 沿途所遇的小气泡因揬触大气泡一 面的液膜薄，因此破裂而归进大气泡里来，被迅速地带 到液面而逸出(圖 11)。应用这个原理来清澄玻疑, 一 为化学方法, 投入發泡剂如氧化俳、硝酸鉸于玻琌液中

\section{第相}

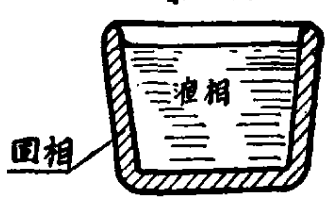

国 10 坡璃的愘炼看作固、

液、气三相的各自反

应及相亘作用

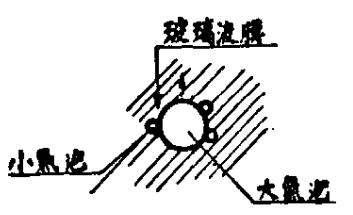

回 11 表示小气泡归入 大气泡里去
以發生大气泡; 一为物理方法, 人工地輸入氧气或引 逝含水植物如維卜到玻唡液底部以产生大气泡。

（3）避免温度的忽源忽落。火熖气氛与玻唡所吸 收的气体間在一定温度下有一定的平衡, 一般在温度 下降时玻玹液所能吸收的气体量增加，所以火石玻璃 在高温时可看見夹有小气泡，但随着温度的下降，小 气泡逐逐激消失了。但若温度下降后再次上升則气泡 将再度出現, 所以玻璃清澄后温度必須一順地下降, 不可忽涱忽落。

（4）将無气泡的液态固定下来。物理化学过程的 进行都需要一定的时間，若时間太短則原来状态可以 保持下来，故高温下的状态可用快速冷却方法使它保
持到低温下，例如鋼的淬火就是这个道理。在光详玻 璃熔制中也引用了这个办法，如含 $\mathrm{B}_{2} \mathrm{O}_{3} 10 \%$ 的硼码 玻璃在高温例如 $1400^{\circ} \mathrm{C}$ 时可以清澄到气泡全部消 失, 但若从 $1400^{\circ} \mathrm{C}$ 加以筧拌而徐䌅冾却下来, 則 泡又会出現，所以須将在 $1400^{\circ} \mathrm{C}$ 时無气泡的状态用 急速冷却的办法固定下来, 例如急冷到 $1200^{\circ} \mathrm{C}$ 。到 $1200^{\circ} \mathrm{C}$ 后玻璃液所能吸收的气体量已增加, 这时再 加以較长时間擤拌則气泡不再出現。

以上(2) (3) (4)三个办法, 只是减少气泡而不影 响侵腐、揮唚与条紋, 所以肯定是有利的。

(5) 获得挰定的光学常数。因每次熔炼时揮㡎、 侵腐的差別, 所以同一配料可得不同光学常数的玻琌。 为克服这个因难, 需要經过几次改变化学成分达到規 定的光学常数后，把添料、清澄、竸汼等的温度时程 固定下来，使每次熔炼这种玻璃时其揮發、侵窝都相 同, 以获得預定的光学常数。在必要时可在揢炼过程 中用同类型的玻璃渣或适当的生料添加进去作㯰解的 校正。

（6）消除分督和条紋的攂汼。矛盾較大的是㳙除 分層和条紋的攪拌，这个攪拌会增加此㶡侵原料 揮發，有时还产生二次气泡，但分層和条紋是光学玻 琌中必須消灭的敌人, 所以㩭找还是必需的。但在㩭 挥动作中应該采取各項措施以压縮那些附带来的不利 影响。例如使㩭抖器离坛珮壁和底一定距离以减少此 堝㻏筞产物的混入玻璃液內, 同时使这嬶抖在海度下 降时进行，这时㠺堝边温度較中心温度低所以粘度大，

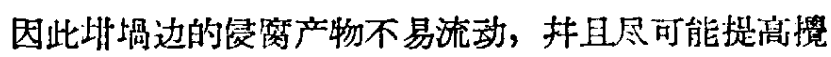

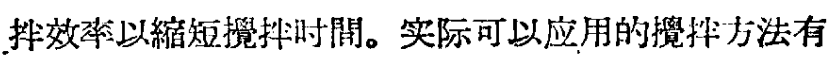

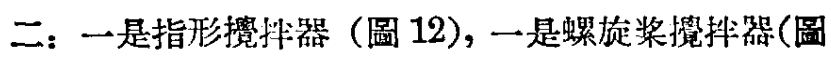
13)。指形攪抖器的优点是在它和玻璃液接触面少,
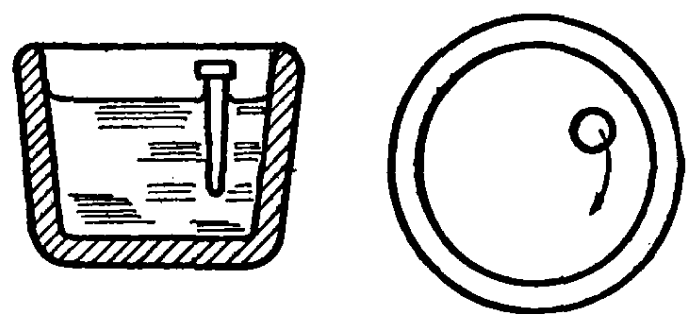

橉 12 指形㗨拌器
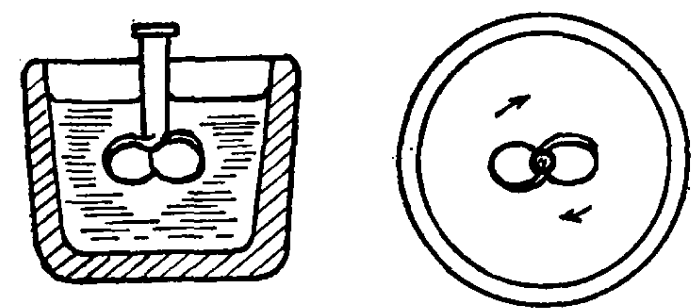

國 13 螺旋浆睍抌器

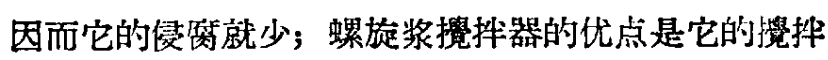
效本高, 可以縮短㩭找时間。㩭拌的作用如下: 
（a）消除玻璃液的分展(Segragation)。玻晍租 分內的氧化物或其矽酸盐的比重各有不同, 例如 $\mathrm{PbO}$ 或其矽酸盐的比重較其它組分，如 $\mathrm{K}_{2} \mathrm{O} 、 \mathrm{Na}_{2} \mathrm{O} 、 \mathrm{ZnO}$ 或其矽酸盐的为大。在熔融时重的組分下沉而輕的組 分上浮，造成上下分首現象而使折射率上下不同。由 于在实际熔炼中温度在 $1300-1450^{\circ} \mathrm{C}$ 之間抹且㘫堝 被封閉于熔㠊內, 不易覌察, 所以我們會根据相似諭

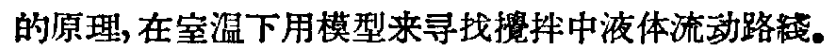
用玻璃燒杯来代替址城, 用透明無色的水玻琌代替玻 施波，紅玻球于燒杯中，作为覌察液体流动的

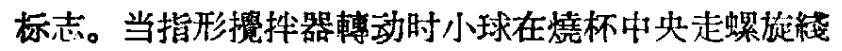
路而上升, 至液面时被攃到垒杯边線又走蛁旋緎路而 下降 (圖 14)。在指形撜抖器变換方向旋轉时 这小紅 球仍是从杯中部上升而沿杯边線下降。用蝶旋浆攚汼 器时若旋轉方向使軸流 (Axial flow) 上升則小紅球

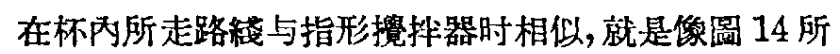
示, 但在同轉速下, 軸流的向上推动力較指形罍抖器

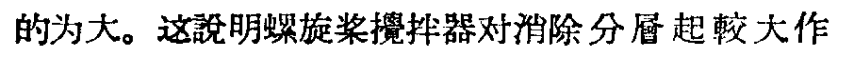
用，因之对熔炼高鉛火石玻哽更为有利。

（b）加扩散面消除条紋。条紋的化学組分的濃 度与其周圍的玻璃洨是有微差的, 这荟度微差所产:生 的扩散运动是很慢的, 但㩭抖将粗条紋攢散成为細条 粒，因之扩大了扩散面积也促进了扩散。㩭抖时除圖 14 所示的片流 (Laminar flow) 以外, 还有攪找器附 近微弱的滥流 (Turbulent flow), 在指形境挥器的 表面有一居侵䆚产物粘着于其上, 产生一交界㕌, 在 这交界庴上的液体速度几乎是零, 离开它勋速度逐漸 增大, 造成一个速度的梯度, 这梯度产生了指形復拌 器后部的漼流, 使玻玹液混合起来, 因而加识了扩散,

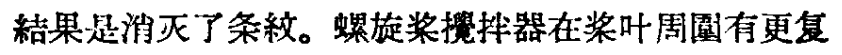
杂的满流。

（c）消除热对流条紋。在降温时由于圤佩中心的 玻唡液温度較高因之密度小而上升, 沿着㘿堝边緗的

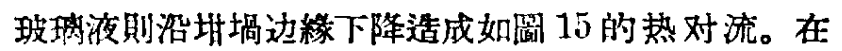

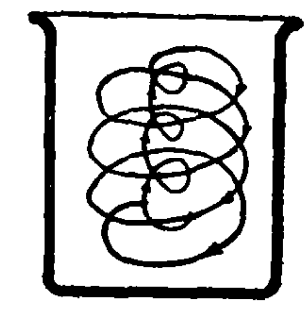

14 賣汼中的㻦液法 动路絨

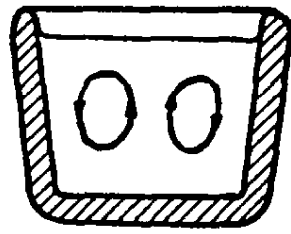

15 坩堝內玻琋液的 热对流
这过程中坩堝与玻琌液交界盾的侵窝产物被对流带到

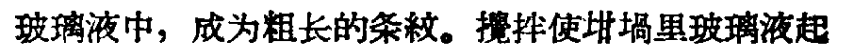

热交換，使温度均匀化，因而阻止了热对流也防止了 热对流条紋。

另外, 玻璃液表面的部分揮如 $\mathrm{K}_{2} \mathrm{O} 、 \mathrm{Na}_{2} \mathrm{O}$ 、 $\mathrm{B}_{2} \mathrm{O}_{3} 、 \mathrm{As}_{2} \mathrm{O}_{3} 、 \mathrm{PbO}$ 等各有不闹，使液面玻唡成分与

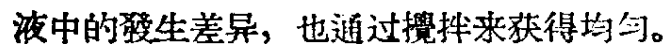

光学玻璃熔炼完成后, 份須成型和退火, 其中包 括若干物理問題将另文处理。

\section{三 光学玻琌生产方法的演进}

光学玻璃的生产方法几乎与炼鋼方法筆局前进， 按其桴展先后，简述如下:

古典法是将玻珤熔成后在训堝中徐冷, 裂成毛塊, 再在毛塊中挑选合格的，加以成型处理成为玻璃碍或 部件毛胚。任圤堝內烈成毛塊过程中合格的玻琌地受 到裂碎的損先, 因之成品漈較低, 是一个缺点。

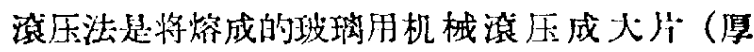

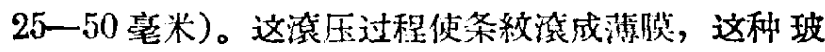
璃可选擇适当方向用于照远鏡的物鏡、目鏡及照相鏡 头上。这方法的成品等很裔，因之成本較低，但其成 品不能用来制造话級的棱鏡。

㙄注法是将揢炼好的玻瑞液澆注到大鉄模里去, 成为一大塊 (厚为 100-200 毫米)，这方法可說是占 典法和涪压法的絬合。

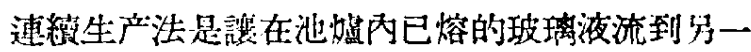
池內攪汼，在擋汼时連續使玻璃液自池內流到一行走 着的带上，因之获得长条的光学玻璃。这尘产一方法与

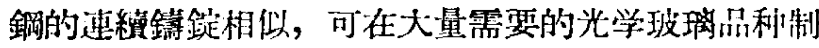
造上应用。所得玻璃的質量較高, 同时成本也低，但 基建投資較大，而且不适用于多品种的生产。

在我国現阶段的工業水平上，要达到投資較低， 同时生产成本地不高的目的, 以采用注注法最为适当。

[1] Moritz von Rohr, P. L. Guinands Anweisung zum Glasschmelzen, Zeitschrift für Instrumentenkund $\epsilon$, XLVIII, 439 (1928).

[2] И. В. Гребөнщиков, Optical Glass in U. S. S. R. (translated from Scientific Leningrad), Glass Industry, 15, 249-251 (1934).

[3] M. L. Huggins and Sun Kuan-Han, Calculation of density and optical constants of glass, J. Amer. Ceram. Soc., 26, 6-11 (1943).

[4] Л. И. Дөмкина, Об апдитивности оптических свойств стекла, ДАН, 58. № 5 стр. 807 (1947).

[b] A. А. Аплен, Расчет оптических свойств, плотности и коэффициента расширения силикатных стокол по их состов, ДАН, 69, стр. 841 (1949). 